\title{
Development and commercialisation of rechargeable wooden LED lamps
}

\author{
Bradley Schultz \\ Returned Field Volunteer, Engineers Without Borders Australia, Melbourne \\ schultz.bradley@gmail.com
}

\begin{abstract}
The focus of this project was to work with local staff at Kathmandu Alternative Power and Energy Group to commercialise a product which would generate recurring income for the organisation, to enable staff to learn the process of commercialisation and to provide employment and skills in the local community. Rechargeable Light Emitting Diode (LED) lamps were deemed suitable for these aims, as they are a simple product, yet one that is urgently required in Nepal due to the prevalence of 'load-shedding'-scheduled electrical blackouts. After reviewing the market, it was found that it would be impossible to compete with the price of cheap imported Chinese rechargeable LED lamps, so an alternative approach was taken. This involved sourcing wooden off-cuts from a local furniture factory and transforming them into attractive desk lamps, with the target market being affluent Nepalis, ex-pats living in Nepal and tourists. Successful initial sales were achieved through a Kathmandu-based ex-pat email group, hotel-markets and souvenir stores. KAPEG staff have continued the project, producing variations on the initial design including Himalayan rock salt lamps, employing local people to manufacture lamps and selling them at markets in Kathmandu. Staffing and marketing challenges remain to ensure the lamp manufacture and sales continue.
\end{abstract}

KEYWORDS: LED, lighting, lamp, commercialisation, Nepal.

1

\section{INTRODUCTION}

Kathmandu Alternative Power and Energy Group (KAPEG) is a small organisation located in a village near Dhulikhel, Nepal, which is striving to develop and commercialise alternative energy products which will help people in Nepal improve their access to electricity (Freere et al, 2008). KAPEG aims to keep the financial benefits from their work within Nepal by building products locally and developing a worldclass professional Engineering team. KAPEG is set up as a company, owned by its staff, with a charter that states that any profits will be invested in the community.

KAPEG staff are all university educated with Engineering degrees, however there is a lack of commercialisation experience in the team - a skill which is vital if products such as wind turbines and micro-hydropower are to be a success. Additionally, KAPEG currently relies on funding from research grants - which typically are once off injections of funding, making it difficult to run the business long term. It was desired that alternative forms of recurring income be found. As part of EWB Australia's volunteer placement scheme, the author, who has over 8 years of product commercialisation experience, worked with the team at KAPEG for 5 months with the aim of imparting commercialisation skills and beginning the process of creating recurring revenue through commercialisation of a product. It was suggested that an LED lighting product warranted further investigation as a suitable candidate.

\section{METHODOLOGY}

Initially, research into the requirements for lighting in Nepal was performed. Along with access to safe drinking water and sanitation, access to lighting is one of the major development challenges facing Nepal (Sharma et al, 2005). Currently, villages with no electricity use kerosene lamps for lighting, which are expensive to run and cause respiratory and eye health problems (Sharma et al, 2005). There are currently several NGO-run projects to address these issues such as the Solar Tuki ("Lamp") project which aims to train local entrepreneurs to build and sell lamps (Sharma et al, 2005). Other projects include Light Up The World (LUTW) (Irvine-Halliday, 2000), which is now international but originally started in Nepal, and various individual NGO projects. 


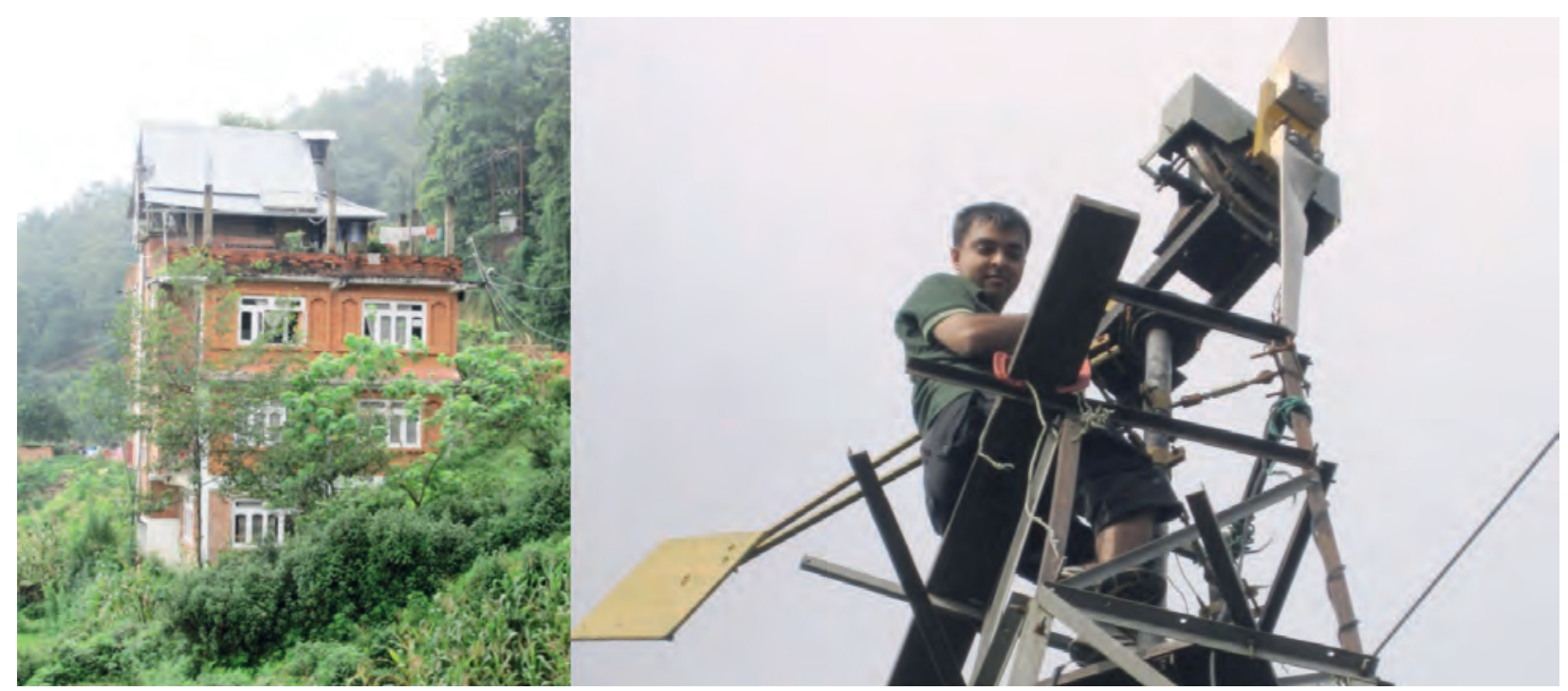

Figure 1: KAPEG head office (left) and prototype wind turbine (right).

In addition to requirements for villages with no access to electricity, there is the requirement for every household in Nepal to have battery powered lighting, as Nepal suffers from 'load-shedding' blackouts due to a shortage of electricity, which is predominantly provided by hydropower. Load-shedding means that the electricity is shared amongst different districts, meaning most households in Nepal have between 2 and 16 hours per day without electricity, depending on the time of year.

The above NGO-run projects made significant headway into the diffusion of solar lighting into villages in Nepal, however the cost of commercially available lighting products has now decreased markedly, meaning more people can access lighting without the need for NGO projects. Research into these other lamps consisted of visits to shops and markets in Kathmandu and Dhulikhel as well as visits to NGOs who have been working with LED lighting projects. LED is the lighting technology of choice due to its low power consumption and long bulb-life. It was found that a wide variety of rechargeable LED lamps were available, in varying qualities. It was readily apparent that it would be impossible to compete with most of these lamps on a price basis, as the cost of the components as purchased off-the shelf from electronic component stores in Kathmandu would be more than most of the cheap Chinese and Indian import lamps cost in total.

Example lamp costs included NRs 750 (A\$8.84) for a good quality mains rechargeable LED lamp with 44 LEDs and a $6 \mathrm{~V} 4.2$ Ah sealed lead acid battery (the same battery later used in the wooden desk lamps) running for 4 to 24 hours depending on mode. For NRs 150 (A\$1.70), a smaller lamp was available that included a $4 \mathrm{~V} 0.6$ Ah battery and charged directly from a normal 240 VAC light bulb socket, running for several hours. This was a very low quality lamp, but the price point was low.

Investigations were also conducted into electronic components available in Kathmandu in order to compare prices of components to the cost of lamps. Once again, the quality of components available

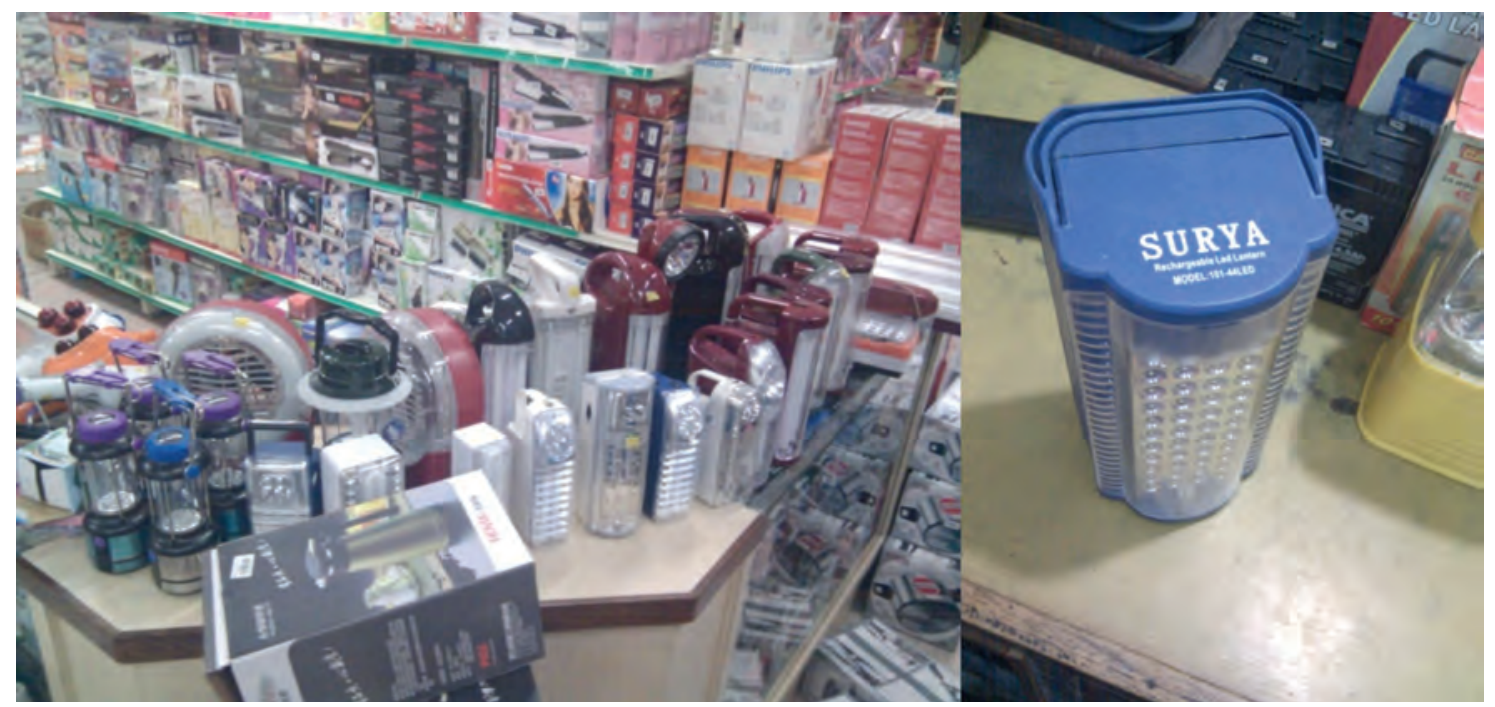

Figure 2: Variety of lamps available in a store in Kathmandu (left) and a rechargeable lamp with $6 \mathrm{~V}$ 4.2 Ah SLA battery, 44 LEDs and integrated charger for NRs 750 (A\$8.60). 


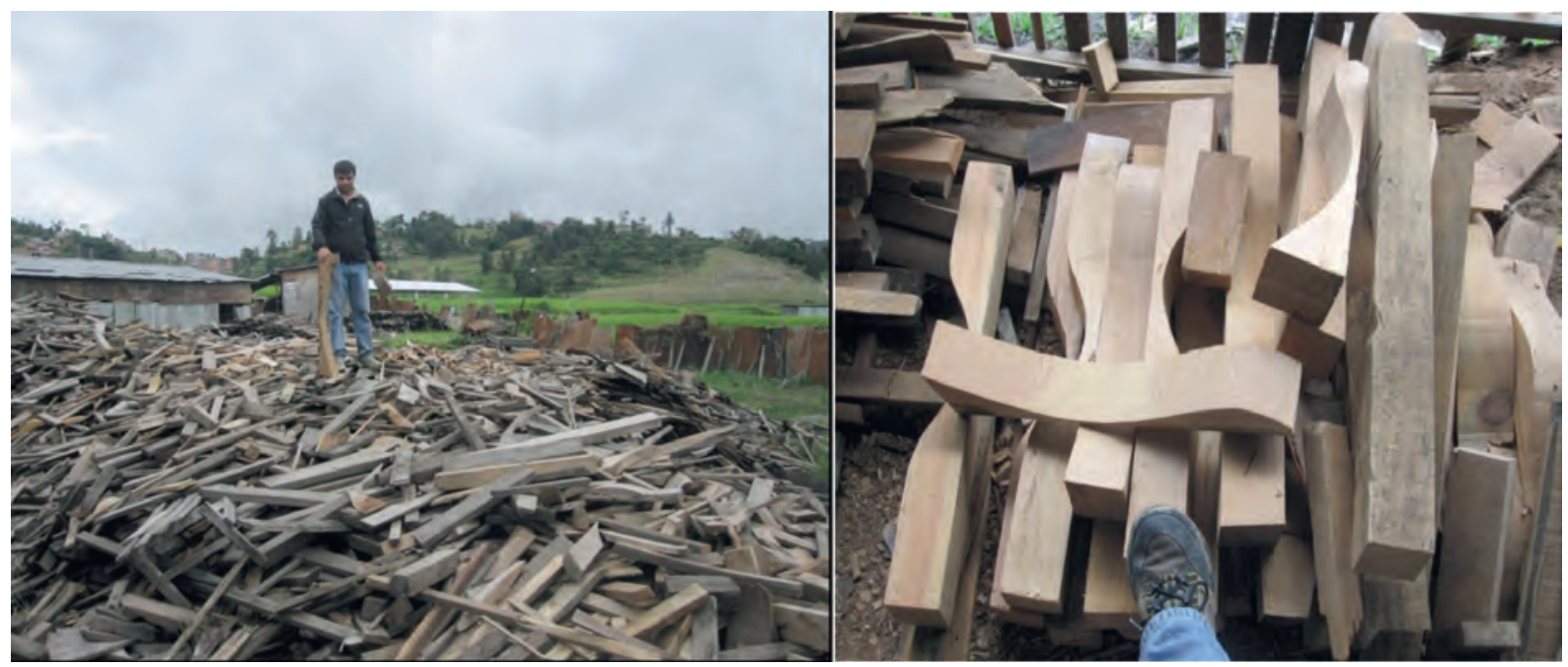

Figure 3: $\quad$ Pile of wood off-cuts at Shaan Furniture (left) and the off-cut type ultimately chosen for the LED desk lamp.

varied widely, but on the whole components were of low quality. During this time, the beginnings of a database of electronic component shops and the good quality components they sold was collated. This database is now available on the KAPEG website (www.kapeg.com.np) and anyone is able to submit new information to it via email.

In light of the above research, it was decided that it would be too difficult to compete directly with low cost commercial LED lighting products, meaning an alternative approach was required. One of Nepal's largest furniture factories, Shaan Furniture, is located in Banepa, close to the KAPEG office. KAPEG has an ongoing engineering consulting arrangement with Shaan Furniture and has worked with the owner in various ways including solar wood drying and repair of electrical equipment.

Investigations were undertaken into the wood offcuts available at the furniture factory. It was found that there were numerous amounts of off-cuts, currently chipped and burned as part of the wood treatment process. It was thought that a some of the off-cuts which were of a particular shape, were large enough and suitably shaped to be shaped into LED lamps. A wooden LED lamp would be a unique product, could potentially be significantly more attractive than plastic equivalents and could potentially fetch a higher price.

Design of the lamps was then conducted, focussing on making the lamps look attractive. Large amounts of time spent on shaping would were needed to achieve this. Electronic design was kept very simple. Volt, 4.2 Ah batteries were used and were charged using simple resistor charging circuits. LEDs were driven with simple resistor current limiting as opposed to more complex constant current designs. An LED was included to confirm that the lamp was charging.

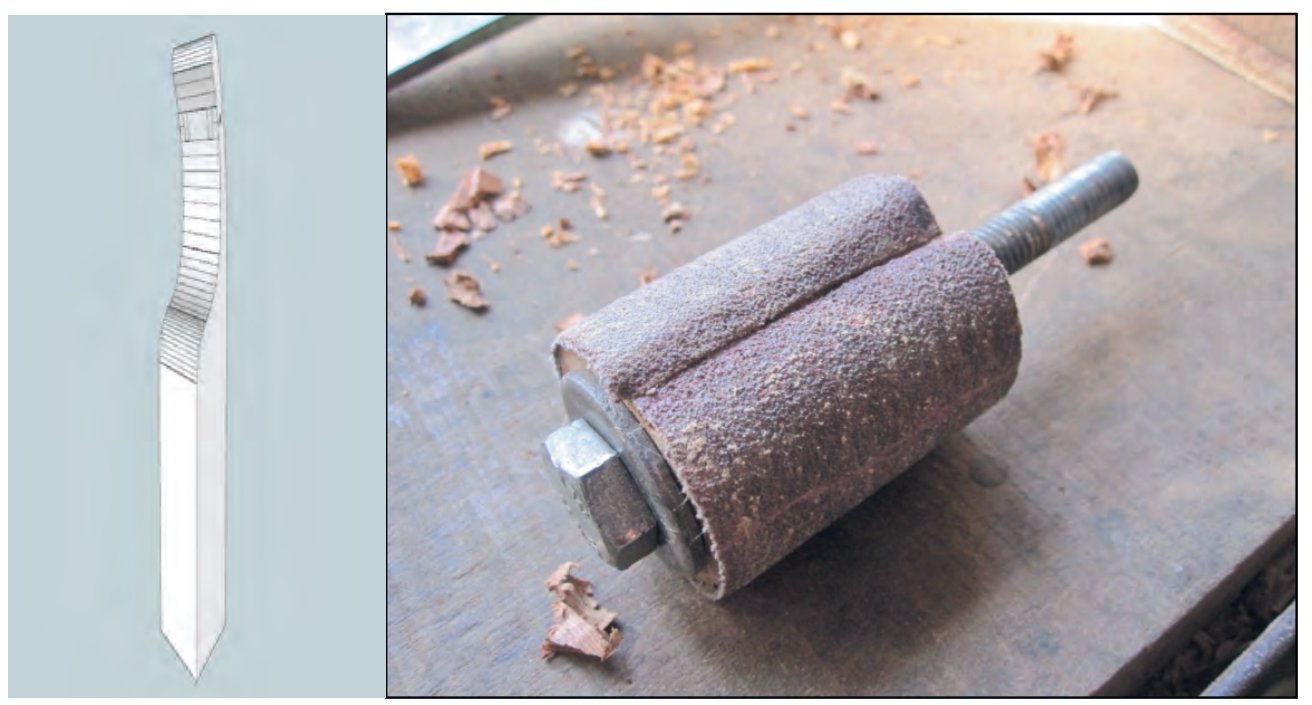

Figure 4: $\quad$ Lamp design mocked up in Google Sketchup (left) and a sanding wheel fashioned out of bolt, sandpaper and a piece of wood (right). 


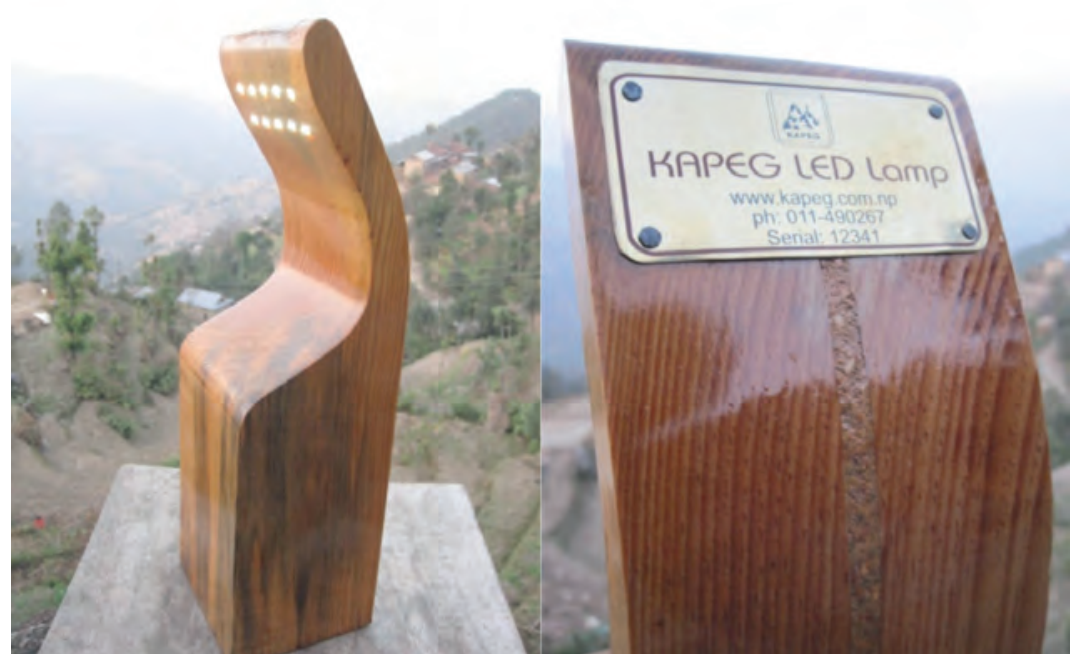

Figure 5: Finished prototype lamp. These photos were emailed out to market the lamps initially.

Several prototype lamps were constructed. Challenges at this point included difficulties shaping the wood with very limited tools and also coping with load-shedding, meaning electricity for power tools was only available for a few hours per day. Obtaining high quality tools and components is difficult in Nepal meaning that tools often and easily break, causing delays and extra costs.

The final lamp runs for around 20 hours, providing enough light to read by and ambient light to light an entire average room. The selling price was set at NRs 2500 (A \$28.64) - a high price compared to other plastic lamps available, but comparable to wooden souvenirs available in souvenir stores in Kathmandu.

\section{HIMALAYAN ROCK SALT LAMPS}

Additionally, lamps were developed that used wood off-cuts as the base, with 1 to 2 LEDs shining up into a piece of Himalayan rock salt. This salt is available in various colours at many Nepali markets in Kathmandu, and the result is a very attractive lamp which provides some ambiance in a dark room. Small batteries were included inside the lamps and standard Nokia-brand mobile phone chargers used to charge the lamps.

\section{MARKETING}

The target market for the LED desk lamp was affluent Nepalese, ex-pats living in Nepal and tourists. Initial test marketing of the lamps was performed via email to a Kathmandu email list which is commonly used by many ex-pats to share information about events and general advice on living in Kathmandu. Additionally, an online order form was set up on the KAPEG website using Google Forms / Google Documents.

Initial response was extremely positive, with orders for around 12 desk lamps and 6 salt lamps being taken - an ideal amount for an initial small batch. These initial orders were manufactured mainly by the author's counterpart at KAPEG, a recent engineering graduate. Once manufactured and tested, they were hand-delivered to the customers, with most customers being happy with the lamps according to initial feedback. There was some negative feedback based around the plaque on the back of the desk lamps, which presents a difficult challenge as the plaque is actually placed to cover electronics in the lamps. In later versions, a plain plaque with no branding was used on some lamps to minimise unsightliness.

It was around this stage that the author finished his volunteer placement in Nepal and returned to Australia, however communications continued via email and it was necessary to conduct some remote project management to ensure timely delivery of lamps. This was made possible with the use of Google Documents as a tool for managing orders. This approach however has not since been continued by KAPEG staff.

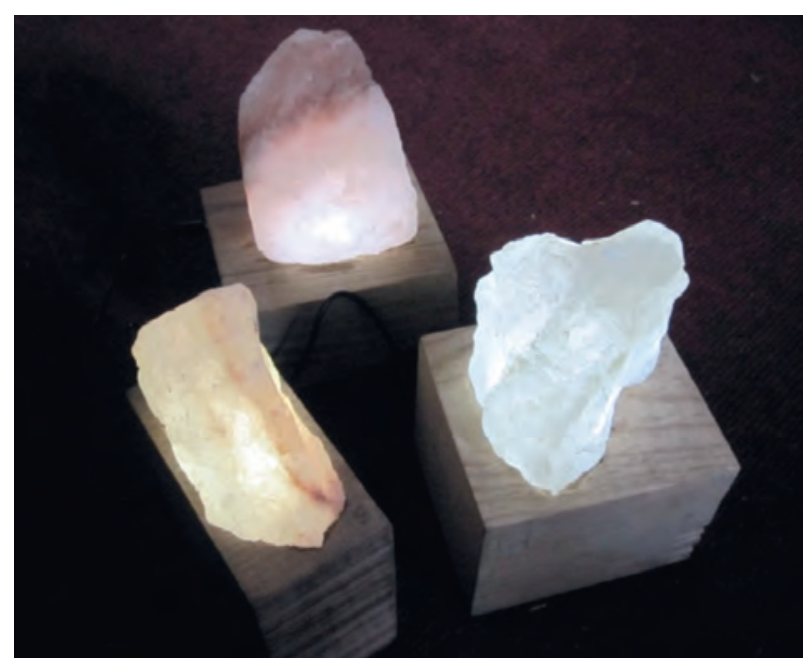

Figure 6: Initial prototype Himalayan Rock Salt lamps. 
Several souvenir shops in Kathmandu were visited, and most expressed interest in stocking the lamps on consignment. There are several markets in Kathmandu which Western ex-pat frequent. One of these is the weekly markets at Summit Hotel at which a stall was set up to sell the lamps.

\section{5}

\section{CONCLUSION AND EVALUATION}

Since the author's departure from Nepal, work on the LED lamps has continued, although at a reduced pace. This is due to various issues, including turnover of staff at KAPEG and the ongoing problem of KAPEG being committed to many projects.

It remains to be seen whether the LED lamps become a profitable product for KAPEG, due to the issues listed above. However, several local high school students have been employed part time shaping the wood for the lamps and KAPEG staff have continued to occasionally sell lamps at markets in Kathmandu. Several souvenir stores in Kathmandu have sample stock on their shelves. In order for the lamps to be profitable, it would be necessary for them to be completely manufactured by local people rather than KAPEG Engineers due to different pay rates.

Over the past 12 months, KAPEG staff have developed several variations on the lamp design based on different wood off-cuts and feedback from customers. Enquiries have been received from overseas as to the possibility of exporting the lamps, but this is probably too difficult to achieve at this stage. Based on the positive feedback gained in Australia on the lamps that the author brought back with him, an export market may be viable at some point.

While it is true that these LED lamps are not contributing directly to remote villages in Nepal, they have the potential to achieve the original aims of the project, which were to build commercialisation experience within the KAPEG team and to provide a recurring income to the organisation. Additional benefits include the re-use of wood that would otherwise be discarded, the provision of jobs and training to villagers who live near the KAPEG office and the beginnings of a new industry in Dhulikhel.

\section{ACKNOWLEDGEMENTS}

The author would like to acknowledge the assistance and inspiration provided by Peter Freere, who's brainchild this project was. The author would also like to acknowledge the efforts of the Pramod Ghimire and the KAPEG team who work tirelessly on such projects aimed at bettering their beautiful country.

\section{REFERENCES}

Freere,P, Lamichhane, C, Shrestha, G, Ghimire, P, Sharma, R, Sinha, R \& Acharya, P 2008, 'Starting a Technical Business in Nepal', in International Workshop on Natural and Low-Cost Materials in Wind Energy Technologies, Dhulikhel, Nepal, November 10-12, 2008, DTU Risø, Denmark.

Irvine-Halliday, D, Craine, S, Upadhyaya, MR \& IrvineHalliday, G, 2000, "Light Up The World - Nepal Light Project and Everest," IEEE Canadian Review, vol. 36, pp. 14-18, Fall 2000.

Light for All - Delivery Mechanismfor Solar Tuki (Solar Lamp), 2008, Centre for Renewable Energy, Nepal, Jwagal, Lalitpur, viewed $9^{\text {th }}$ January 2012, Centre for Renewable Energy.

Sharma, DK, Shrestha JN, Shrestha BR 2005, 'Low Cost Lighting System to Replace the Kerosene Lamps',Paper presented to the World Renewable Energy Regional Congress, Jakarta, Indonesia, 18-21 April 2005.

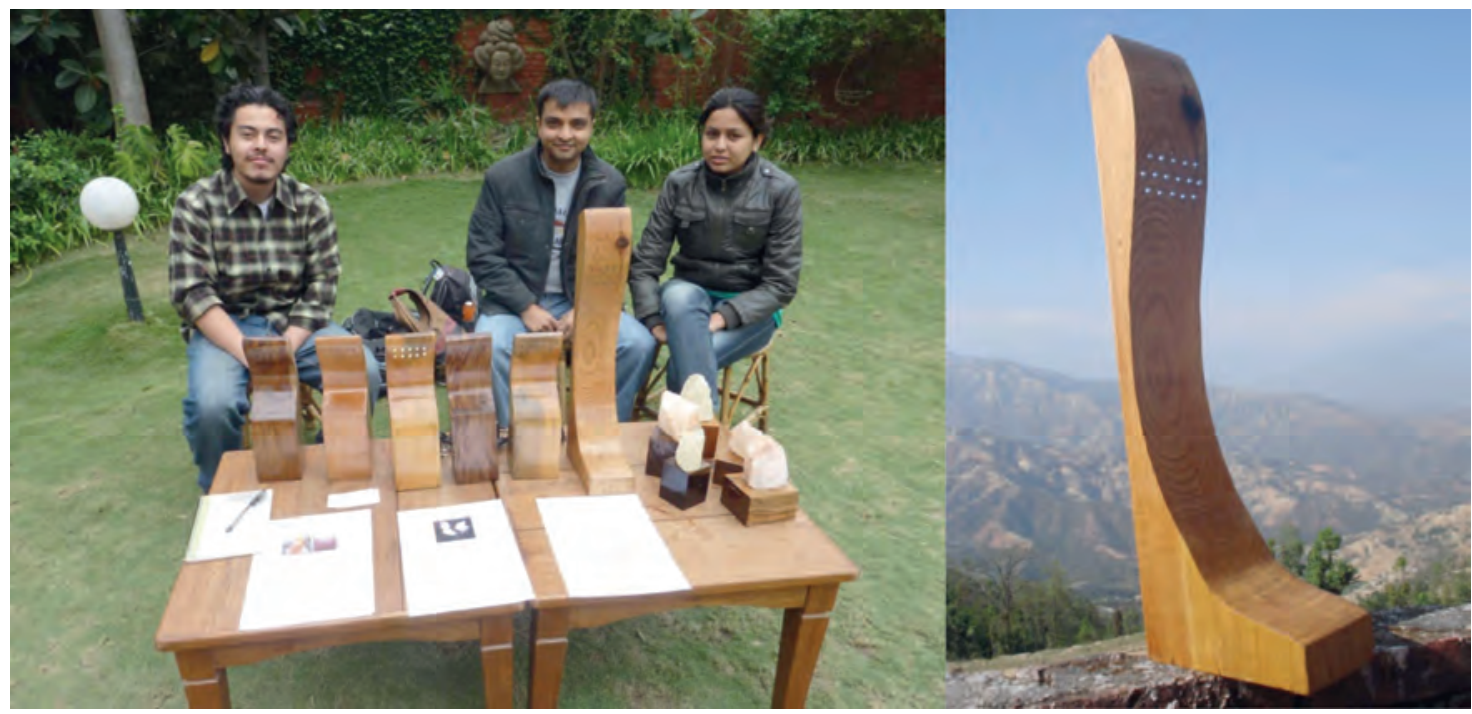

Figure 7 : KAPEG staff selling LED lamps at the Summit Hotel markets in Kathmandu markets (left) and a variation on the desk lamps, developed recently (right). 
